\title{
Ribonucleoprotein Immunoprecipitation (RIP) Analysis
}

Jennifer L. Martindale ${ }^{1}$, Myriam Gorospe ${ }^{1}$, Maria L. Idda ${ }^{1, \$}$

${ }^{1}$ Laboratory of Genetics and Genomics, Biomedical Research Center, National Institute on Aging Intramural Research Program, National Institutes of Health, Baltimore, USA; ${ }^{\$}$ Present address: Istituto di Ricerca Genetica e Biomedica, CNR, Sassari, Italy

* For correspondence: marialaura.idda@irgb.cnr.it

\begin{abstract}
[Abstract] RNAs and RNA-binding proteins (RBPs) can interact dynamically in ribonucleoprotein (RNP) complexes that play important roles in controlling gene expression programs. One of the powerful ways to investigate changes in the association of RNAs with an RBP of interest is by immunoprecipitation (IP) analysis of native RNPs. RIP (RNP immunoprecipitation) analysis enables the rapid identification of endogenous RNAs bound to an RBP and to monitor time-dependent changes in this association, as well as changes in response to different metabolic and stress conditions. The protocol is based on the use of an antibody, typically an anti-RBP antibody, to immunoprecipitate the RNP complex. The RNA within the immunoprecipitated complex can then be isolated and further studied using different approaches such as PCR, microarray, Northern blot, and sequencing analyses. Among other advantages, RIP analysis (i) measures RNP associations in many samples relatively quickly, (ii) can be adapted easily to different endogenous RBPs, and (iii) provides extensive information at low cost. Among its limitations, RIP analysis does not inform on the specific sites of interaction of an RBP with a given target RNAs, although recent adaptations of RIP have been developed to overcome this problem. Here we provide an optimized protocol for RIP analysis that can be used to study RNA-protein interactions relevant to many areas of biology.
\end{abstract}

Keywords: RNA-binding proteins, Ribonucleoprotein complex, Post-transcriptional regulation, Gene expression, RNA target

[Background] The post-transcriptional fate of RNA is strongly regulated by its dynamic association with RNA-binding proteins (RBPs) forming ribonucleoprotein (RNP) complexes that govern all aspects of RNA metabolism, including precursor RNA splicing, and RNA modification, folding, translation, stability, transport, and storage (Glisovic et al., 2008). Additionally, alterations in RBP functions have been implicated in many human pathologies, including neurodegeneration (Kang et al., 2014; Ravanidis et al., 2018), immune diseases (Idda et al., 2018; Yoshinaga and Takeuchi, 2019) and cancers (Pereira et al., 2017). Thus, there is immense interest in developing methods to investigate RNPs and identify target RNAs that can illuminate the function of RBPs in physiology and disease. Excellent reviews of the most common methods for RNP analysis are available (McHugh et al., 2014; Cipriano and Ballarino, 2018; Licatalosi et al., 2019).

Originally developed in the Keene laboratory (Tenenbaum et al., 2000; Keene et al., 2006), RNP immunoprecipitation (RIP) analysis is most often used to measure the association of a specific RBP with 
RNAs in intact cells. The method described here is suitable for most RBPs, but the efficiency is strongly dependent on the quality of the antibodies, the abundance of the RBP analyzed, and the methods to assess bound RNA. In a nutshell, RIP analysis entails the immunoprecipitation (IP) of a specific RBP under mild conditions that preserve the RNP complexes in the IP, whereupon the RNAs present in the RNP complex can be isolated and further analyzed by a range of RNA-detection methods, such as reverse transcription (RT) followed by quantitative PCR (RT-qPCR) analysis (Figure 1A) or other techniques such as Northern, RNA-seq, or microarray analyses (Tenenbaum et al., 2000; Keene et al., 2006; Zhao et al., 2010). RIP analysis is well suited to measure many RNAs at once and to detect changes in binding to RNAs as a function of time or stimulus in a fast and inexpensive way. While this RIP procedure does not reveal the actual site of RBP binding to a target RNA, adaptations of this method including a cross-linking step (crosslinking IP, CLIP) or not (Digestion Optimized-RIP, DO-RIP) do permit the identification of RNA sequences bound by the RBP, although these analyses are often more timeconsuming and technically challenging (Nicholson et al., 2017; Lee and Ule, 2018; Wheeler et al., 2018; Lin and Miles, 2019).

In summary, RIP identifies RNAs associated with a given RBP and informs on changes in the intracellular composition of RNPs in response to different stimuli. RIP has been used in many laboratories to identify endogenous RBPs associated with endogenous RNAs in a wide range of cell types. In this protocol, we describe the use of RIP in the human monocytic leukemia line THP-1, although the same protocol can be used for other cell lines.

\section{Materials and Reagents}

Note: Please ensure that all reagents and materials are confirmed to be RNase-free. We normally use company-certified RNase-free solutions and materials for RIP assay.

1. MicroAmp ${ }^{\circledR}$ optical 384-well reaction plate (Thermo Fisher Scientific, Applied Biosystems ${ }^{\mathrm{TM}}$, catalog number: 4309849)

2. Safe-Lock 1.5-ml Eppendorf Tubes (Eppendorf, catalog number: 0030120086)

3. ThermoGrid ${ }^{\mathrm{TM}}$ rigid strip 0.2-ml PCR tubes (Denville Scientific, catalog number: C18064)

4. Disposable cuvettes, $1.5-\mathrm{ml}$ (Stockwell Scientific, catalog number: 2410)

5. Protein A-Sepharose ${ }^{\circledR}$ (PAS) preswollen beads (GE Healthcare, catalog number: 17-1279-02)

6. Appropriate primary antibody recognising a specific RBP of interest. Here we use antibody antiDRBP76/ILF3 (NF90) as an example (Millipore, catalog number: ABF1070)

7. A species-appropriate isotype control. For NF90 RIP, we use normal mouse IgG control (Santa Cruz Biotechnology, catalog number: sc-2025)

8. DNase I (RNase-free) (Thermo Fisher Scientific, catalog number: AM2222)

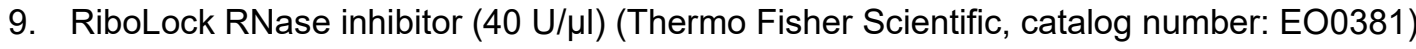

10. Random primers $(100 \mu \mathrm{M})$ (Thermo Fisher Scientific, catalog number: SO142)

11. dNTP mix (10 mM each) (Thermo Fisher Scientific, catalog number: R0192) 
12. Maxima ${ }^{\mathrm{TM}}$ reverse transcriptase (Thermo Fisher Scientific, catalog number: EP0741) and $5 \mathrm{x} R T$ buffer (provided with Maxima Reverse Transcriptase)

13. Proteinase $\mathrm{K}$ Solution $(20 \mathrm{mg} / \mathrm{ml}$ ) (Thermo Fisher Scientific, catalog number: AM2546)

14. Nuclease-free water (Thermo Fisher Scientific, catalog number: AM9930)

15. Dulbecco's phosphate-buffered saline (DPBS) (Thermo Fisher Scientific, catalog number: 100100-15)

16. Halt Protease \& Phosphatase inhibitor cocktail (100x) (Thermo Fisher Scientific, catalog number: 78442)

17. TRIzol ${ }^{\mathrm{TM}}$ (Thermo Fisher Scientific, catalog number: AM9738)

18. DTT (Sigma-Aldrich, catalog number: 43815)

19. UltraPure $1 \mathrm{M}$ Tris- $\mathrm{HCl}(\mathrm{pH} 7.5)$ (Thermo Fisher Scientific, catalog number: 15567-027)

20. $1 \mathrm{M} \mathrm{KCl}$ solution (Sigma-Aldrich, catalog number: 60142)

21. $1 \mathrm{M} \mathrm{MgCl}_{2}$ solution (Sigma-Aldrich, catalog number: M1028)

22. 0.5 M EDTA (Thermo Fisher Scientific, catalog number AM9261)

23. $5 \mathrm{M} \mathrm{NaCl}$ solution (Sigma-Aldrich, catalog number: 71386)

24. $20 \%$ SDS solution (Sigma-Aldrich, catalog number: 05030 )

25. GlycoBlue ${ }^{T M}(15 \mathrm{mg} / \mathrm{ml})$ (Thermo Fisher Scientific, catalog number: AM9515)

26. KAPA SYBR ${ }^{\circledR}$ FAST ABI prism 2x qPCR master mix (Kapa Biosystems, catalog number: KK4605), or SYBR Green from other vendors

27. Nonidet ${ }^{\mathrm{TM}}$ P-40 (IGEPAL ${ }^{\circledR}$ CA-630, Sigma, catalog number: I8896)

28. Chloroform (Sigma-Aldrich, catalog number: C2432)

29. Isopropanol (Sigma-Aldrich, catalog number: 19516)

30. Ethanol (Sigma-Aldrich, catalog number: 51976)

31. Bio-Rad Protein Assay Dye Reagent Concentrate (for Bradford assay) (Bio-Rad, catalog number: 5000006)

32. Polysome extraction buffer (PEB) (see Recipes)

33. NT2 buffer (see Recipes)

\section{Equipment}

Note: Other analogous equipment can be used for this protocol.

1. PCR strip tube rotor, mini centrifuge C1201 (Denville Scientific, catalog number: C1201-S [1000806])

2. NanoDrop ${ }^{\mathrm{TM}}$ One spectrophotometer (Thermo Fisher Scientific, catalog number: ND-ONE-W)

3. Eppendorf Thermomixer ${ }^{\circledR} R$ (Eppendorf, catalog number: 022670581)

4. Refrigerated centrifuge (Eppendorf, model: 5430R)

5. SmartSpec ${ }^{\mathrm{TM}}$ Plus (Bio-Rad Laboratories, catalog number: 1702525) or another spectrophotometer with $595 \mathrm{~nm}$ wavelength

6. Tube Revolver/Rotator (Thermo Fisher Scientific, catalog number: 88881001) 
7. Veriti ${ }^{\mathrm{TM}}$ 96-well thermal cycler (Thermo Fisher Scientific, catalog number 4375786)

8. QuantStudio ${ }^{\mathrm{TM}} 5$ Real-Time PCR System, 384-well (Thermo Fisher Scientific, catalog number: A28140)

9. Cell culture hoods and $\mathrm{CO}_{2}$ Incubator for cell culture

\section{Procedure}

Note: Please be sure to optimize your conditions. Empirical tests are required to optimize RIP conditions and to obtain the optimal signal-to-noise ratio results, meaning that target RNAs are enriched in the specific RBP IP compared to the IgG IP control while nonspecific, non-target RNAs are equally present in both the IgG and RBP IP samples.

\section{Day 1}

A. Antibody coating of Protein A Sepharose (PAS) beads

1. Use $60 \mu \mathrm{l}$ of PAS beads for each reaction.

2. Wash the beads 1 time with $1 \mathrm{ml}$ of ice-cold of NT2 by inverting the tube a few times, centrifuge for 2 min at 2,000 $\times \mathrm{g}, 4{ }^{\circ} \mathrm{C}$ and resuspend the beads in $60 \mu \mathrm{INT} 2$ buffer.

3. Add $5 \mu \mathrm{g}$ of the antibody of interest (anti-NF90 in this case) or control lgG (normal mouse IgG in this case) to $60 \mu$ l of PAS beads.

Notes:

a. Be sure to match the antibody of interest with a species-compatible control lgG. The isotype control is used to determine the specific versus the non-specific signals (RNAs) which are immunoprecipitated due to the immunoglobulin isotype rather than the specific RBP.

b. The amount of antibody required for IP will depend on the antibody quality and the RBP analyzed. The optimal amount of antibody should be tested beforehand by doing IP with this protocol using 2, 5, 10 and $20 \mu \mathrm{g} \mathrm{Ab.}$

4. Add $200 \mu \mathrm{l}$ NT2 buffer.

5. Bind overnight on rotator at $4{ }^{\circ} \mathrm{C}$.

B. Preparation of cultured cells

Prepare cells as needed. For THP-1, the day before RIP, the cells should be plated at a concentration of $0.5 \times 10^{6} / \mathrm{ml}$. For two IP reactions (IgG control IP and RBP IP), a total of $1 \times 10^{7}$ cells is needed.

Note: For adherent cells, one 10-cm culture dish is typically enough for two IP. 


\section{Day 2}

C. Preparation of the Antibody coated PAS beads

1. Add $1 \mathrm{ml}$ of ice-cold NT2 and wash the beads by inverting the tube a few times, centrifuge for 2 min at 2,000 $\times g, 4{ }^{\circ} \mathrm{C}$, and repeat once.

2. After the last spin, remove excess NT2 buffer and resuspend the beads in $50 \mu \mathrm{NT} 2$ buffer. The PAS/Ab beads are now ready to be used, keep on ice.

D. Preparation of Ribonucleoprotein (RNP) lysate from cultured cells

1. Collect the volume of THP-1 cells necessary to have $1 \times 10^{7}$ cells for the two IP reactions and centrifuge for $5 \mathrm{~min}$ at $1,000 \times \mathrm{g}, 25^{\circ} \mathrm{C}$.

2. Wash with PBS and centrifuge again for 5 min at $1,000 \times g, 25^{\circ} \mathrm{C}$.

Note: It is best to use fresh lysate immediately.

3. Loosen the final cell pellet by gently flicking the tube and add $1 \mathrm{ml}$ of ice-cold PEB buffer supplemented with RNase inhibitors and protease inhibitors.

4. Mix by pipetting a few times (do not vortex), place on ice for $10 \mathrm{~min}$.

5. Spin for $15 \mathrm{~min}$ at $10,000 \times \mathrm{g}, 4^{\circ} \mathrm{C}$. Transfer supernatant (RNP lysate) to fresh microfuge tubes.

6. (Optional step) Preclearing (not necessary for RIP followed by RT-PCR).

a. Preclear the supernatant with $10 \mu \mathrm{g}$ of $\operatorname{lgG} 1$ antibody control for $30 \mathrm{~min}$ at $4{ }^{\circ} \mathrm{C}$ with rotation.

b. Add $50 \mu \mathrm{PAS}$, incubate for $30 \mathrm{~min}$ at $4{ }^{\circ} \mathrm{C}$ with rotation.

c. Spin down at $2,000 \times g$ for $2 \mathrm{~min}$ at $4{ }^{\circ} \mathrm{C}$. Save supernatant in a fresh tube. This is your precleared lysate.

7. Measure protein concentration of the lysate by the Bradford assay. A typical concentration when using these cells is $\sim 5 \mu \mathrm{g} / \mu \mathrm{l}$. You will need $500-1,000 \mu \mathrm{g}$ of lysate for each RIP.

E. Immunoprecipitation of RNPs

1. Aliquot the precoated PAS/Ab (around $50 \mu \mathrm{l}$ ) into microfuge tubes.

2. Prepare a master mix using the following additives for each reaction:

$300 \mu \mathrm{l}$ NT2 buffer

$10 \mu \mathrm{l} 0.1 \mathrm{M}$ DTT (do not add the DTT to the pellet directly as this will reduce the antibody and the IP will not work)

$10 \mu$ RiboLock

$33 \mu \mathrm{l} 0.5 \mathrm{M}$ EDTA

3. Add $500 \mu \mathrm{g}$ RNP lysates.

Note: The amount of lysate required for IP will depend on the RBP, the cell type, and the antibody used. Optimal amounts of lysates should be determined beforehand by testing IP with 250,500 , and $1,000 \mu \mathrm{g}$ of material.

4. Add NT2 buffer to $1 \mathrm{ml}$.

5. Incubate for $1-2 \mathrm{~h}$ at $4{ }^{\circ} \mathrm{C}$ with rotation.

6. Spin down at $2,000 \times \mathrm{g}, 2 \mathrm{~min}, 4^{\circ} \mathrm{C}$. Discard supernatant. 
7. Wash pellet 5 times* $^{*}$ each with $1 \mathrm{ml}$ of ice-cold NT2 buffer. Spin between washes: 2,000 $\times \mathrm{g}$, $2 \min , 4^{\circ} \mathrm{C}$.

Note: (Optional) Take $100 \mu$ l of beads during the last wash to verify the IP by Western blot analysis (more details below in Notes).

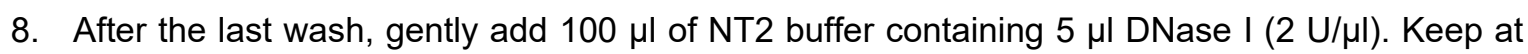
$37^{\circ} \mathrm{C}$ for $10 \mathrm{~min}$.

Note: It is critical not to resuspend the beads harshly-simply eject the contents of the pipettor and place at $37^{\circ} \mathrm{C}$ swirling delicately. It is important not to shake at this step!

9. Add $1 \mathrm{ml}$ of NT2 buffer and spin at 2,000 $\times \mathrm{g}, 2 \mathrm{~min}$, discard supernatant.

10. Make a master mix using the following reagents for each reaction: $100 \mu \mathrm{l} \mathrm{NT2,} 2.5 \mu \mathrm{l}$ of Proteinase $\mathrm{K}(20 \mathrm{mg} / \mathrm{ml}), 1 \mu \mathrm{l} 10 \% \mathrm{SDS}$. Add $100 \mu \mathrm{l}$ of this master mix to each PAS pellet.

11. Incubate at $55^{\circ} \mathrm{C}$ for 20 min, with gentle mixing.

12. Spin at 2,000 $\times \mathrm{g}, 2 \mathrm{~min}$, collect the supernatant $(\sim 100 \mu \mathrm{l})$ to a fresh tube.

13. To the beads, add $200 \mu \mathrm{l} \mathrm{NT2} \mathrm{buffer,} \mathrm{spin} \mathrm{at} \mathrm{2,000} \times$ g, 2 min, collect the supernatant $(\sim 200 \mu \mathrm{l})$ and combine with the supernatant above. Discard beads.

14. To the combined supernatants $(100 \mu$ l plus $200 \mu \mathrm{l})$, add $700 \mu \mathrm{l}$ of Trizol reagent.

15. Vortex for $1 \mathrm{~min}$ at $25^{\circ} \mathrm{C}$.

16. Extract the RNA according to Trizol manufacturer's instruction.

F. RNA extraction and RT-qPCR analysis

1. Add $200 \mu \mathrm{l}$ chloroform to each sample.

2. Shake the tubes vigorously by hand for $10 \mathrm{~s}$ then centrifuge at $13,000 \times \mathrm{g}$ for $15 \mathrm{~min}$ at $4{ }^{\circ} \mathrm{C}$.

3. Transfer the upper aqueous layer to a fresh microfuge tube containing $1 \mathrm{ml}$ isopropanol and $1 \mu \mathrm{l}$ of Glycoblue.

Note: The upper aqueous layer is generally $70 \%$ of the initial volume of Trizol.

4. Precipitate the RNA by incubating for $10 \mathrm{~min}$ at $25^{\circ} \mathrm{C}$ followed by centrifugation at $13,000 \times \mathrm{g}$ for 15 min at $4{ }^{\circ} \mathrm{C}$.

5. Discard the supernatant and wash the pellet once with $1 \mathrm{ml}$ ice-cold $70 \%$ ethanol.

6. Centrifuge at $13,000 \times g$ for $5 \mathrm{~min}$ at $4{ }^{\circ} \mathrm{C}$ and discard the supernatant.

7. Air dry RNA pellet for $5-10 \mathrm{~min}$ at $25^{\circ} \mathrm{C}$.

8. Dissolve RNA in $20 \mu$ nuclease-free water.

Note: Do not measure $O D_{260}$, as the concentration is very low and this will probably waste most of your sample. Just use 5-10 $\mu$ directly to prepare your cDNA.

9. Use $5 \mu \mathrm{l}$ of the RNA solution for reverse transcription by preparing a $20-\mu \mathrm{l}$ reaction in a $0.2 \mathrm{ml}$ PCR tube containing $5 \mu$ l of prepared RNA, $1 \mu$ random primers, $4 \mu \mathrm{l} 5 \mathrm{x}$ RT buffer, $1 \mu \mathrm{l}$ RiboLock, $1 \mu \mathrm{l}$ dNTP mix and $1 \mu \mathrm{l}$ Maxima reverse transcriptase. Bring to $20 \mu \mathrm{l}$ with Nuclease-free water.

10. Mix and centrifuge for a few seconds.

11. For the CDNA synthesis, use these thermal cycler parameters: $25{ }^{\circ} \mathrm{C}$ for $10 \mathrm{~min}, 50{ }^{\circ} \mathrm{C}$ for $30 \mathrm{~min}$ and $5 \mathrm{~min}$ at $85^{\circ} \mathrm{C}$ (the manufacturer's instructions for Maxima reverse transcriptase). 
12. Dilute the cDNAs with nuclease-free water to $100 \mu$ final volume (1:5 dilution).

13. Prepare $10 \mu \mathrm{l}$ qPCR reactions in a 384-well plate, using the following mix: $5 \mu \mathrm{l} 2 x$ SYBR Green PCR mix, $1 \mu \mathrm{l}$ cDNA, and $4 \mu \mathrm{l}$ primer mix (forward and reverse primers). Use specific primers for mRNAs of interest as well as for 1 or 2 mRNAs encoding housekeeping proteins (e.g., HSP90, ACTB, UBC or GAPDH mRNAs).

14. Cover the plate with optical adhesive film and centrifuge the plate for $10 \mathrm{~s}$ using Plate Spinner to settle the reactions at the bottom of the wells.

15. Use a QuantStudio 5 Real-Time PCR System for qPCR with a cycle set up of 3 min at $95^{\circ} \mathrm{C}$ and 40 cycles of $5 \mathrm{~s}$ at $95^{\circ} \mathrm{C}$ plus $20 \mathrm{~s}$ at $60^{\circ} \mathrm{C}$. When using a primer set for the first time, analyze the dissociation curves to verify that the primer set is optimal in these conditions.

\section{Data analysis}

As mentioned above, RNAs isolated with this RIP protocol can be analyzed by several molecular methods including quantitative RT-PCR (if the RNA binding targets of the RBP are known), microarray, or RNA-seq analyses (for an in-depth unbiased approach). Here we have presented a RIP protocol followed by RT-qPCR analysis (Figure 1A).
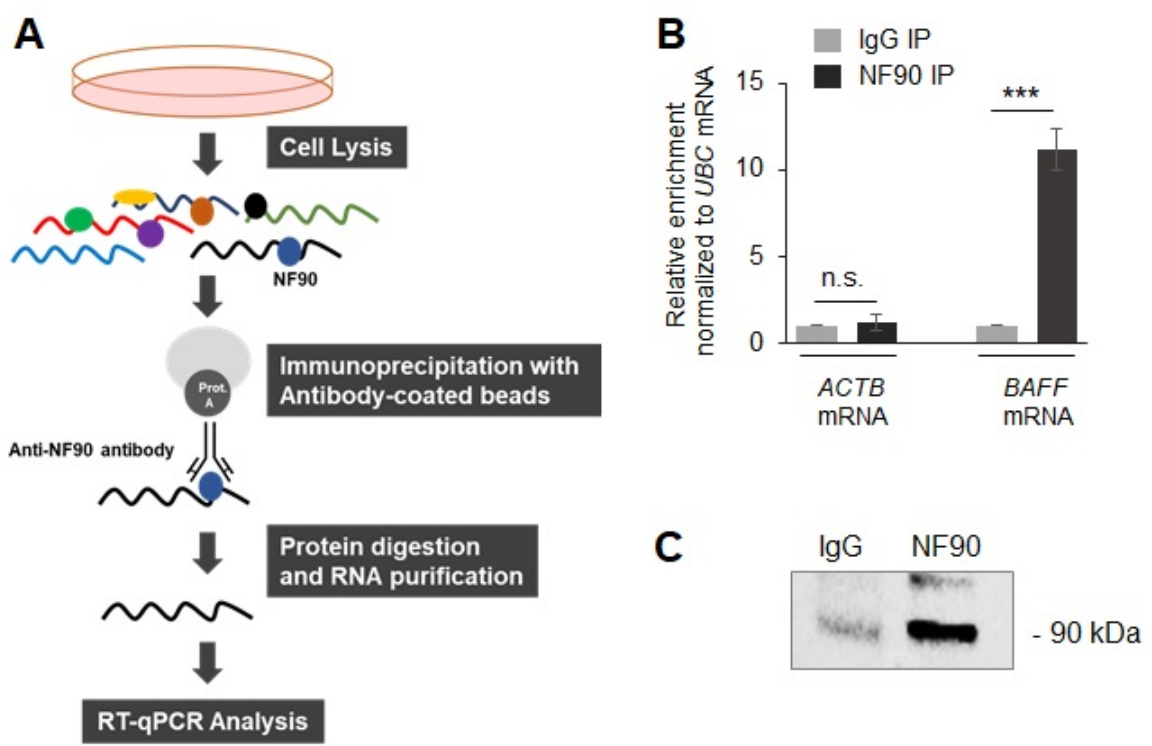

Figure 1. Ribonucleoprotein Immunoprecipitation (RIP) Analysis. A. Schematic of the ribonucleoprotein immunoprecipitation (RIP) assay protocol. B. The association of the RBP NF90 (used here as example) with $A C T B$ and BAFF mRNAs was tested by RIP analysis using anti-NF90 antibody. Following RNA extraction, the abundance of BAFF and ACTB mRNAs in NF90 IP and IgG IP control samples was assessed by RT-qPCR analysis using mRNA-specific primers (ACTB: CATGTACGTTGCTATCCAGGC and CTCCTTAATGTCACGCACGAT; BAFF: CACAATTCAAAGGGGCAGTAA and ACTGAAAAGGAGGGAGTGCAT; UBC: ATTTGGGTCGCGGTTCTTG and TGCCTTGACATTCTCGATGGT). These results were 
normalized to the levels of UBC mRNA in each sample, and then plotted as the enrichment of mRNAs in the NF90 IP relative to the BAFF and ACTB mRNA levels observed in the IgG IP samples. C. After IP using anti-NF90 or IgG antibodies, the presence of NF90 in the IP material was confirmed by Western blot analysis.

Analysis of specific enriched mRNAs should be normalized with a proper 'background' control RNA, a transcript that does not associate specifically with the RBP of interest and allows the user to monitor the evenness of sample input. It is customary to use mRNAs encoding abundant housekeeping proteins, such UBC, GAPDH, or TUB mRNAs, as the nonspecific transcripts. The identification of a good background control RNA, which should yield similar $\mathrm{Ct}$ values in both the IgG control and RBP IP when sample input is even, is fundamental for good-quality results. In the example shown in Figure 1B we used $U B C$ mRNA for background control.

To calculate the fold enrichment of each RIP reaction from $\mathrm{QPCR}$ data, first normalize the Ct value of the target RNA to the $\mathrm{Ct}$ of the control ('housekeeping') mRNA. The conventional representation of the data is by displaying 'fold enrichment' of RNAs in RBP IP relative to IgG IP (the latter, usually displayed as ' 1 ', represents the background mRNA level in the IgG isotype control). To calculate fold enrichments, the normalized RIP fraction value ( $\triangle \mathrm{Ct}$ of target RNA normalized to the 'housekeeping' mRNA) is normalized to nonspecific background (the similar $\triangle \mathrm{Ct}$ calculation of the IgG fraction), to yield the $\Delta \Delta \mathrm{Ct}$ value. The linear conversion of this $\Delta \Delta \mathrm{Ct}$ renders the fold enrichment, which is plotted for BAFF mRNA binding to NF90 in our example (Figure 1B). Fold enrichment was also calculated for a negative control, a transcript (ACTB mRNA in this case) that does not bind NF90, and this control mRNA was found not to be significantly enriched (Figure 1B).

\section{$\underline{\text { Notes }}$}

$\left.{ }^{*}\right)$ Take $100 \mu \mathrm{l}$ of beads during last wash (Step E7) to verify the IP by Western blot analysis, centrifuge briefly, remove the supernatant, and add $30 \mu \mathrm{l}$ SDS loading buffer to the beads. Boil at $100{ }^{\circ} \mathrm{C}$ for $10 \mathrm{~min}$ and load an aliquot on SDS-PAGE gel for Western blot analysis. If the IP is successful, a stronger signal will be visible in the lane in which the RBP of interest was immunoprecipitated, as compared to the IgG control (Figure 1C).

\section{$\underline{\text { Recipes }}$}

Note: It is critical to prepare all the solutions in RNase-free conditions.

1. Polysome extraction buffer (PEB)

$20 \mathrm{mM}$ Tris-HCl, $\mathrm{pH} 7.5$

$100 \mathrm{mM} \mathrm{KCl}$

$5 \mathrm{mM} \mathrm{MgCl}_{2}$

$0.5 \%$ Nonidet P-40 
Add fresh protease and RNase inhibitors each time

2. NT2 buffer

$50 \mathrm{mM}$ Tris $\mathrm{HCl}, \mathrm{pH} 7.5$

$150 \mathrm{mM} \mathrm{NaCl}$

$1 \mathrm{mM} \mathrm{MgCl} 2$

$0.05 \%$ Nonidet P-40

Note: Please keep the NT2 uncontaminated and RNase-free. If the RIP does not work, it is a good bet that NT2 needs to be made fresh.

\section{Acknowledgments}

JM, MG, and MLI were supported by the NIA IRP, NIH. MLI was additionally supported by the National Research Council-Institute for Genetic and Biomedical Research (CNR-IRGB), Italy. This protocol was adapted from articles previously published by the laboratory of JD Keene. The protocol was tested and optimized by different researchers in the Gorospe laboratory, NIA IRP, NIH. We thank D Tsitsipatis and G Delogu for careful review of the manuscript.

\section{Competing interests}

No conflicts of interest or competing interests to declare.

\section{References}

1. Cipriano, A. and Ballarino, M. (2018). The ever - evolving concept of the gene: The use of RNA/protein experimental techniques to understand genome functions. Front Mol Biosci 5: 20.

2. Glisovic, T., Bachorik, J. L., Yong, J. and Dreyfuss, G. (2008). RNA-binding proteins and posttranscriptional gene regulation. FEBS Lett 582(14): 1977-1986.

3. Idda, M. L. Lodde, V. McClusky, W. G., Martindale, J. L., Yang, X., Munk, R., Steri, M., Orrù, V. Mulas, A. Cucca, F., Abdelmohsen, K. and Gorospe M. (2018). Cooperative translational control of polymorphic BAFF by NF90 and miR-15a. Nucleic Acids Res 46(22): 12040-12051.

4. Kang, M. J., Abdelmohsen, K., Hutchison, E. R., Mitchell, S. J., Grammatikakis, I., Guo, R., Noh, J. H., Martindale, J. L., Yang, X., Lee, E. K., Faghihi, M. A., Wahlestedt, C., Troncoso, J. C., Pletnikova, O., Perrone-Bizzozero, N., Resnick, S. M., de Cabo, R., Mattson, M. P. and Gorospe M. (2014). HuD regulates coding and noncoding RNA to induce APP $\rightarrow A \beta$ processing. Cell Rep 7(5):1401-1409.

5. Keene, J. D., Komisarow, J. M. and Friedersdorf, M. B. (2006). RIP-Chip: the isolation and identification of mRNAs, microRNAs and protein components of ribonucleoprotein complexes from cell extracts. Nat Protoc 1(1): 302-307.

6. Lee, F. C. Y. and Ule, J. (2018). Advances in CLIP technologies for studies of protein - RNA 
interactions. Mol Cell 69: 354-369.

7. Lin, C. and Miles, W. O. (2019). Beyond CLIP: advances and opportunities to measure RBPRNA and RNA-RNA interactions. Nucleic Acids Res 47(11):5490-5501.

8. Licatalosi, D. D., Ye, X. and Jankowsky, E. (2019). Approaches for measuring the dynamics of RNA-protein interactions. Wiley Interdiscip Rev RNA 11(1): e1565.

9. McHugh, C. A., Russell, P. and Guttman M. (2014) Methods for comprehensive experimental identification of RNA-protein interactions. Genome Biology 15(1): 203.

10. Nicholson, C. O., Friedersdorf, M. and Keene J. D. (2017). Quantifying RNA binding sites transcriptome-wide using DO-RIP-seq. RNA 23(1):32-46.

11. Pereira, B., Billaud, M. and Almeida, R. (2017). RNA-binding proteins in cancer: old players and new actors. Trends Cancer 3(7): 506-528.

12. Ravanidis, S., Kattan, F. G. and Doxakis, E. (2018). Unraveling the pathways to neuronal homeostasis and disease: mechanistic insights into the role of RNA-binding proteins and associated factors. Int J Mol Sci 19(8): pii: E2280.

13. Tenenbaum, S. A., Carson, C. C., Lager, P. J. and Keene J. D. (2000). Identifying mRNA subsets in messenger ribonucleoprotein complexes by using cDNA arrays. PNAS 97(26): 14085-14090.

14. Wheeler, E. C., Van Nostrand E. L. and Yeo G. W. (2018). Advances and challenges in the detection of transcriptome-wide protein-RNA interactions. Wiley Interdiscip Rev RNA 9(1): e1436.

15. Yoshinaga, M. and Takeuchi, O. (2019). RNA binding proteins in the control of autoimmune diseases. Immunol Med 42(2): 53-64.

16. Zhao, J., Ohsumi, T. K., Kung, J. T., Ogawa, Y., Grau, D. J., Sarma K., Song J. J., Kingston R. E., Borowsky M. and Lee J. T. (2010). Genome-wide identification of polycomb-associated RNAs by RIP-seq. Mol Cell 40(6): 939-953. 